EXTENDED REPORT

\title{
The often overlooked digital tuft: clues to diagnosis and pathophysiology of neuropathic disease and spondyloarthropathy
}

\author{
B M Rothschild, S Behnam
}

Ann Rheum Dis 2005;64:286-290. doi: 10.1136/ard.2004.021303

See end of article for authors' affiliations

Correspondence to: Dr B Rothschild, Arthritis Center of Northeast Ohio, 5500 Market, Youngstown, $\mathrm{OH} 44512$, 330-783-5900, USA bmr@neoucom.edu

Accepted 1 June 2004

\begin{abstract}
Objective: To assess diagnostic implications of abnormalities of the pedal digital tufts and to identify features to facilitate distinguishing of spondyloarthropathy and leprosy.

Background: Better criteria for distinguishing between these disorders are necessary if their character, natural history, and evolution are to be understood.

Methods: Pedal $x$ rays of 91 consecutive patients with diabetes, 21 alcoholic patients, 100 with spondyloarthropathy, 8 with scleroderma, and 137 with leprosy, and 188 defleshed skeletons of individuals with alcoholism, syphilis, cerebrovascular disease, and paraplegia from the Terry and Hamman-Todd collections were examined for evidence of osseous and articular pathologies. Digital tuft abnormalities were divided into irregularity, divot, flattening, resorption, whittling, and fragmentation.

Results: Tuft divots were more common in alcoholics than in diabetic, and were more common in both than in the other groups studied. Tuft flattening was limited to alcoholic and neurosyphilis groups. Tuft whittling was especially prominent among individuals with spondyloarthropathy, contrasted with leprosy and diabetes. Aligned fractures were more common in diabetics than individuals with leprosy. Misaligned fractures were limited to individuals with leprosy and neurosyphilis. Leprosy and spondyloarthropathy were complicated by phalangeal and metatarsal whittling more commonly than other diseases studied. Background pedal abnormalities, derived from individuals with cardiovascular syphilis, cerebrovascular accidents, and paraplegia, was limited to abnormal divots only.

Conclusions: Pedal digital tufts undergo a variety of pathological alterations useful in the recognition of disorders traditionally considered neuropathic in aetiology and in distinguishing differential considerations. Tuft flattening appears specific for alcoholism and neurosyphilis, and misaligned fractures seem specific for neurosyphilis and leprosy, providing differential assistance related to spondyloarthropathy. Conversely, periosteal reaction distinguishes spondyloarthropathy from leprosy.
\end{abstract}

$\mathrm{R}$ ecognising neuropathic diseases and distinguishing between them presents significant clinical challenge. Pedal manifestations of diabetes and leprosy have been studied according to different criteria, compromising comparison and differential. ${ }^{1-9}$ Other neurological diseases generally lack even this information, ${ }^{35}$ and have ignored tufts. Distinguishing neuropathic disease from disorders such as spondyloarthropathy and scleroderma suffers from an even more incomplete comparative database. ${ }^{5} 10$

Diabetes, leprosy, and alcoholism are the only neuropathic disorders currently occurring with sufficient frequency to allow epidemiological analysis. ${ }^{311}$ While neurosyphilis is uncommon today, it was common in the early portion of the 20th century and is well represented in skeletal collections from that period. ${ }^{12}$ Alcoholism, also represented in those skeletal collections, provides a standard for comparison of macroscopically visible skeletal changes with those seen on $x$ ray.

Radiological evaluation was performed on sequential patients with diabetes, leprosy, alcoholism, spondyloarthropathy, and scleroderma, and compared with macroscopic findings in defleshed skeletons from sequential individuals who had died with alcoholism and neurosyphilis. Background frequency of pedal alterations was derived from individuals with cardiovascular syphilis, cerebrovascular accidents, and paraplegia related deaths (disorders not known to be associated with neuropathic joint disease ${ }^{56}$ and that were uniquely documented in sufficient numbers for epidemiological analysis in the Terry and Hamman-Todd (skeleton) collections).

\section{METHODS}

Institutional review board approval was obtained at the initiation of this study. The clinical sample consisted of 91 consecutive patients with type 1 and type 2 diabetes and 21 alcoholic patients with foot $x$ rays attending the St Elizabeth Hospital Medical Center (Youngstown, Ohio) in a 2 year period; 100 consecutive patients with spondyloarthropathy and 8 with scleroderma seen at the Arthritis Center of Northeast Ohio (Youngstown, Ohio); and 137 individuals with leprosy seen at the Toronto Hospital outpatient leprosy clinic (Toronto, Ontario, Canada) and at the United States Public Health Service Hospital (Carville, Louisiana, USA). Diagnosis of diabetes was based on glycosylated haemoglobin $>6.5 \%$; alcoholism was based on patient history and physical findings ( signs of chronic liver disease, spider telangiectasias, testicular atrophy, gynaecomastia); spondyloarthropathy and scleroderma were diagnosed according to standard criteria of axial and peripheral subchondral erosions, fusion and new bone formation, and dermatological and vascular changes and systemic manifestations, respectively; and leprosy was diagnosed from clinical (hypopigmented hypesthetic plaques, resorption of phalanges, leonine faces) and bacteriological findings. ${ }^{13-16}$ The $x$ rays were reviewed for evidence of osseous and articular pathologies.

Skeletons of individuals with alcoholism, cardiovascular syphilis, and cerebrovascular disease were macroscopically examined from the Terry (National Museum of Natural History, Smithsonian, Washington, DC, USA) and HammanTodd (Cleveland Museum of Natural History, OH, USA) 
collections. The collections consist of 1636 and 3701 skeletons of individuals who died in the St Louis and Cleveland areas, respectively, in the early part of this century. ${ }^{12}$ The skeletons were derived from cadavers of unclaimed status that, after autopsy, were subjected to de-fleshing with sodium hydroxide to remove soft tissues, thus preserving tufts, but not necessarily distal fragmented components. The medical condition and cause of death records were available for most of the individuals.

Digital tuft abnormalities were divided (fig 1) into irregularity, divot, flattening, resorption, whittling, and fragmentation. ${ }^{1}$ Divot was defined as focal defect; resorption, as loss of distal portion; whittling, as concentric narrowing; fragmentation, as destruction with multiple residual bony fragments; and irregularity, simply as irregular tuft surface. Flattening was recognised when a portion of the tuft was absent, as if a knife had removed it. When only the proximal portion of the distal phalanx remained, the term "button" was used. Osteopenia was recognised on the basis of the metacarpal index (second metacarpal corticotrabecular bone ratio) correlated with the metatarsal index. ${ }^{5}$

Concurrence of both authors was required for categorisation of abnormalities. Ten films were analysed blindly at separate times to assess intra-observer variability. Statistical analysis was performed with $\chi^{2}$ and Fisher's exact test to determine statistical differences (at $p=0.05$ ) between the disorders and between macroscopic and radiological findings as to tuft abnormalities, fracture occurrence and character, diaphyseal whittling and resorption, periosteal reaction (other than focal), joint fusion, and neuropathic arthritis. Stress fractures were identified on the basis of very focal periosteal reaction. ${ }^{5}$ Fifth distal interphalangeal joint fusion was primary, unless otherwise indicated.

\section{RESULTS}

Demographics revealed comparable populations. Neither intra-observer nor inter-observation variation was noted. While women were less commonly represented in the syphilis and clinical alcoholism groups, statistical significance $\left(\chi^{2}=2.068\right)$ was not achieved. Significant differences in osseous abnormalities were observed between the groups.

\section{Tuft abnormalities}

Tuft divots (fig 1, table 1) were more common in alcoholics (clinical, although not in the defleshed skeletal sample) than in diabetics $\left(\chi^{2}=4.264, \mathrm{p}<0.04\right)$, and were present in both of these groups more commonly than in the other groups studied $\left(\chi^{2}=8.12, \mathrm{p}<0.005\right)$. Tuft flattening was limited to alcoholic and neurosyphilis groups $\left(\chi^{2}=37.80, \mathrm{p}<0.0001\right)$. Tuft whittling was especially prominent among individuals with spondyloarthropathy, compared with leprosy and diabetes $\left(\chi^{2}=5.13, p<0.025\right)$. The latter group manifested tuft whittling more frequently than the other groups studied $\left(\chi^{2}=14.94, \mathrm{p}<0.0005\right)$. The frequency of tuft resorption was indistinguishable between the leprosy, diabetes, and spondyloarthropathy groups $\left(\chi^{2}=3.50\right)$, but more common than in the other groups studied $\left(\chi^{2}=21.30, p<0.0002\right)$. Tuft irregularity was indistinguishable between the groups $\left(\chi^{2}=2.31\right)$, with tuft fragmentation more common in leprosy $\left(\chi^{2}=8.42, \mathrm{p}<0.005\right)$. Residual buttons were found only in leprosy and diabetes $\left(\chi^{2}=8.42, \mathrm{p}<0.005\right)$.

\section{Diaphyseal changes Fracture}

Aligned fractures were more common in diabetics than in individuals with leprosy $\left(\chi^{2}=6.80, \mathrm{p}<0.01\right)$ (table 1$)$. Such fractures were less common in other groups studied $\left(\chi^{2}=13.71, \mathrm{p}<0.0005\right)$. Misaligned fractures, however, were limited to individuals with leprosy and neurosyphilis $\left(\chi^{2}=8.42, \mathrm{p}<0.005\right)$.

\section{Diaphyseal changes}

Leprosy and spondyloarthropathy were complicated by whittling changes in phalangeal and metatarsal diaphyses more commonly than other groups studied $\left(\chi^{2}=21.34\right.$, $\mathrm{p}<0.0001)$. Osteopenia was associated with the whittling in leprosy, but not in spondyloarthropathy. Pencil in cup deformity was rare and not statistically distinguishable in frequency between the groups studied $\left(\chi^{2}=2.82\right)$.

Stress fractures were more common in alcoholics than in individuals with spondyloarthropathy $\left(\chi^{2}=4.50, \mathrm{p}<0.03\right)$, and afflicted both groups more commonly than the other groups studied $\left(\chi^{2}=17.71, \mathrm{p}<0.0003\right)$. Periostitis (unrelated to stress fractures) was more common in individuals with diabetes and spondyloarthropathy than in the other groups studied $\left(\chi^{2}=19.58, \mathrm{p}<0.0001\right)$.

Fifth distal interphalangeal joint fusion was uncommon in diabetics $\left(\chi^{2}=13.75, \mathrm{p}<0.0005\right)$ compared with other groups studied, but indistinguishable in frequency within those other groups $\left(\chi^{2}=0.81\right)$.

\section{Controls}

Background frequency of pedal abnormalities, determined on the basis of individuals with cardiovascular syphilis, cerebrovascular accidents, and paraplegia, was limited to only abnormal divots, fifth distal interphalangeal joint fusion, and occasional stress fractures (table 1 ).

\section{DISCUSSION \\ Pedal digital tufts}

Pedal digital tufts undergo a variety of pathological alterations (fig 1) that are useful in recognition of disorders traditionally considered neuropathic in aetiology and in distinguishing them from differential diagnoses. ${ }^{1-10}$ Such alterations are rare in non-neuropathic diseases and even among individuals who have succumbed to cerebrovascular accidents. As the only abnormalities observed in the latter groups were divots, observation of any other tuft changes should stimulate search for neuropathic disease, spondyloarthropathy, or scleroderma.

Limitation of tuft flattening to alcoholics and individuals with neurosyphilis suggests diagnostic specificity. The special propensity for divot occurrence in alcoholics suggests a possible contributing role of sensory abnormalities. Implications are unclear as the skeletal and clinical sample were disparate on this point $\left(\chi^{2}=11.675, \mathrm{p}<0.01\right)$. This may relate to differences in "habitat" of alcoholics between the present and the early part of the last century (from which the skeletal collections derive).

A variety of other tuft abnormalities was prominent in diabetes and leprosy. Whittling, resorption, and button formation were equally represented, while fragmentation was limited to individuals with leprosy. Whittling was especially prominent among individuals with spondyloarthropathy, with frequencies similar to that of leprosy and diabetes.

\section{Diaphyseal and distal interphalangeal joint alterations}

Fusion of the fifth distal interphalangeal joint is a congenital phenomenon that was equally represented in all groups (but not assessed among individuals with leprosy), with the exception of diabetics. This raises the possibility that there could be a relationship between diabetes propensity and the gene coding for fifth distal interphalangeal joint fusion.

Aligned fractures were especially common among diabetics, more so than in leprosy and less common in other 
Table 1 Pedal digital tuft and diaphyseal abnormalities as a function of underlying disease

\begin{tabular}{|c|c|c|c|c|c|c|c|c|c|}
\hline Disease & Leprosy & Diabetes & & Alcoholism & $\begin{array}{l}\text { Neuro- } \\
\text { syphilis }\end{array}$ & $\begin{array}{l}\text { Non- } \\
\text { neuro- } \\
\text { syphilis }\end{array}$ & Otherł & $\begin{array}{l}\text { Spondylo- } \\
\text { arthropathy }\end{array}$ & Scleroderma \\
\hline Derivation & CXR & CXR & CXR & $\mathrm{SE}$ & $\mathrm{SE}$ & SE & SE & CXR & CXR \\
\hline Average age & 46 & 59 & 49 & 48 & 43 & 52 & 60 & 60 & 61 \\
\hline $\operatorname{Sex}(\% \mathrm{~F})$ & 45 & 55 & 29 & 50 & 28 & 24 & 55 & 50 & 74 \\
\hline $\begin{array}{l}\text { Number } \\
\text { examined }\end{array}$ & 137 & 91 & 21 & 66 & 29 & 28 & 65 & 100 & 8 \\
\hline \multicolumn{10}{|l|}{ Character* } \\
\hline Tuft & - & - & - & - & - & - & - & - & \\
\hline Divot & $7(5)$ & $16(18)$ & $8(40)$ & $3(5)$ & $3(10)$ & 4 (14) & $1(2)$ & $12(12)$ & $2(25)$ \\
\hline Flattened & 0 & 0 & 11 (52) & $17(26)$ & $10(34)$ & 0 & 0 & 0 & \\
\hline Whittled & $9(7)$ & $7(8)$ & 0 & 0 & 0 & 0 & 0 & $15(15)$ & \\
\hline Resorption & 24 (18) & $8(9)$ & $1(5)$ & 0 & 0 & 0 & 0 & $9(9)$ & $1(13)$ \\
\hline Irregular & $9(7)$ & $2(2)$ & 0 & 0 & 0 & 0 & 0 & 0 & \\
\hline Fragmented & $11(8)$ & 0 & 0 & 0 & 0 & 0 & 0 & 0 & \\
\hline Phalangeal & - & - & - & - & - & - & - & - & \\
\hline Button & $12(9)$ & 12 (13) & 0 & 0 & 0 & 0 & 0 & 0 & \\
\hline \multicolumn{10}{|l|}{ Fracture } \\
\hline Aligned & $11(8)$ & $18(20)$ & $2(10)$ & $2(3)$ & $2(7)$ & 0 & $6(9)$ & $3(3)$ & \\
\hline Misaligned & $11(8)$ & 0 & 0 & 0 & $2(7)$ & 0 & 0 & 0 & \\
\hline Whittling & 17 (10) & $1(1)$ & 0 & 0 & 0 & 0 & 0 & $6(6)$ & \\
\hline Resorption & 0 & 0 & 0 & 0 & 0 & 0 & 0 & 0 & $1(13)$ \\
\hline Pencil in cup & $9(7)$ & 0 & 0 & 0 & 0 & 0 & 0 & $2(2)$ & \\
\hline Periostitis & $9(7)$ & $19(21)$ & $1(5)$ & $1(2)$ & 0 & 0 & 0 & $25(25)$ & $1(13)$ \\
\hline Stress $f_{x} \dagger$ & $3(2)$ & $3(4)$ & 5 (24) & $8(12)$ & $3(10)$ & $2(7)$ & $6(9)$ & $8(8)$ & 1 (13) \\
\hline $\begin{array}{l}5^{\text {th }} \text { DIP } \\
\text { fusion NR }\end{array}$ & $12(13)$ & $9(43)$ & 23 (35) & $7(24)$ & $10(36)$ & $26(40)$ & 34 (34) & 2 (13) & \\
\hline
\end{tabular}

groups studied. Misaligned fractures were limited to individuals with neurosyphilis and leprosy, providing possible diagnostic assistance.
Diaphyseal whittling was leprosy and spondyloarthropathy associated (noting one isolated occurrence in a diabetic), in contrast to tuft changes, which also afflicted diabetics. Stress
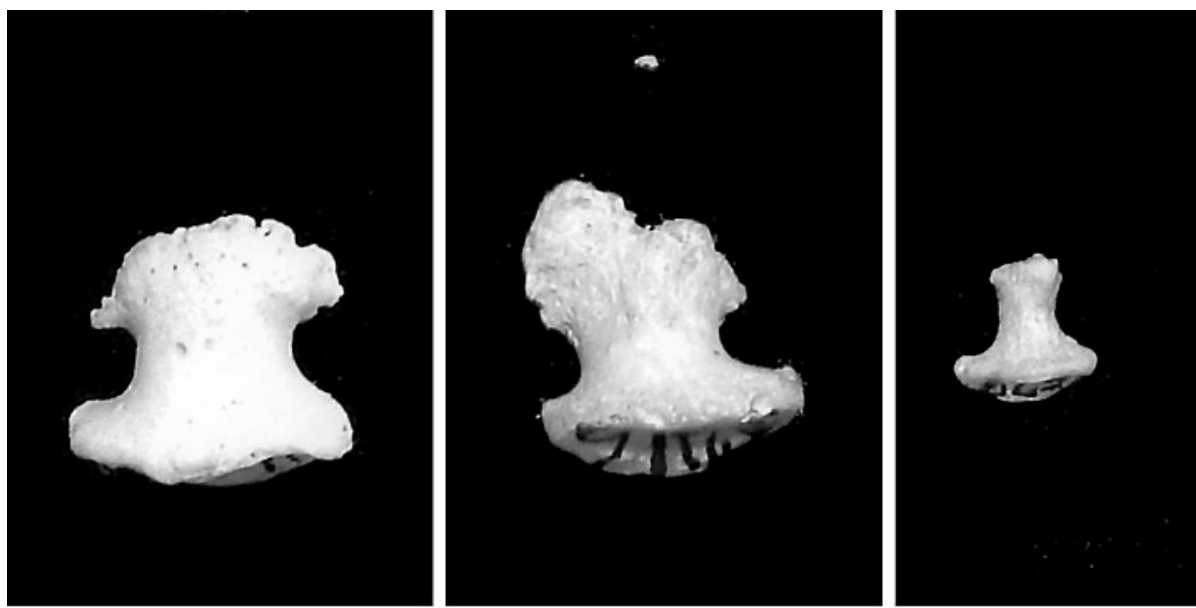

Figure 1 Anterior macroscopic (top and left bottom image) and anterior-posterior radiological bottom middle and right image) views of distal pedal phalanges. Normal tuft from individual who had a cerebrovascular accident (top left); tuft divot from individual with diabetes (top middle); tuft resorption from individual with leprosy (top right); tuft flattening from individual with alcoholism (bottom left); tuft whittling with proximal phalanx fracture from individual with diabetes (bottom middle); and tuft fragmentation from individual with leprosy (bottom right).

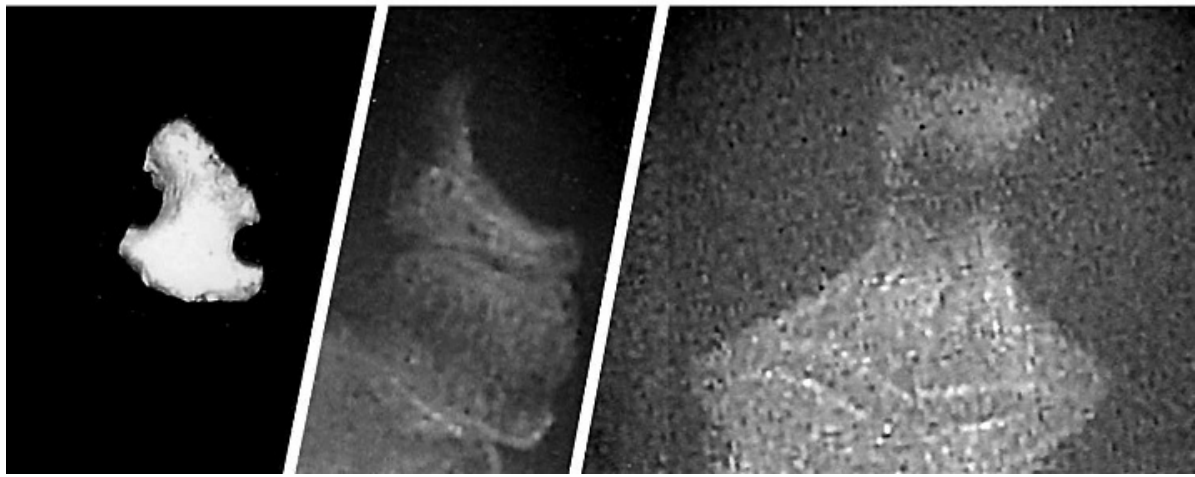




\begin{tabular}{|c|c|c|c|c|c|c|}
\hline Disease & Whittling & Resorption & Flattening & Divot & Irregularity & Fragmentation \\
\hline Leprosy & + & + & & & + & + \\
\hline Diabetes & + & + & & + & & \\
\hline Alcoholism & & + & + & + & & \\
\hline Neurosyphilis & & & + & + & & \\
\hline Non-neurosyphilis & & & & + & & \\
\hline Spondyloarthropathy & + & + & & + & & \\
\hline Scleroderma & & + & & + & & \\
\hline Controls (other*) & & & & + & & \\
\hline
\end{tabular}

fractures were common in alcoholics, less so in spondyloarthropathy. Non-stress fracture related periosteal reaction was more common in diabetics.

\section{Resorption implications}

The aetiology of diaphyseal resorption has been a matter of conjecture. Anjum et $a l^{17}$ reported resorption of an entire proximal humerus from avascular necrosis after a fracture. In our study, diaphyseal resorption, as opposed to whittling, was found only in scleroderma (a single case), in spite of the small numbers of scleroderma patients with $x$ rays available for study. This contrasts with the aforementioned diaphyseal whittling, which may have differential importance for leprosy, diabetes, and spondyloarthropathy, and with tuft resorption, found with leprosy, diabetes, alcoholism, spondyloarthropathy, and scleroderma.

\section{Disease specificity}

Alcoholics were especially susceptible to tuft divots and flattening, stress fractures, and distal interphalangeal joint fusion (table 2). Diabetics were afflicted with tuft divots, whittling, resorption, button formation, aligned fractures, and non-stress fracture related periostitis. Neurosyphilis was associated with flattening of digital tufts and misaligned fractures, as well as divots, aligned fractures, stress fractures, and fifth distal interphalangeal joint fusion. Leprosy was associated with digital tuft whittling, resorption, fragmentation, button formation, both aligned and misaligned fractures, and shaft whittling. Spondyloarthropathy was associated with both tuft and shaft whittling, tuft resorption, stress fractures, and periostitis.

\section{Archaeological implications with clinical application} Much of our perspective of leprosy has been derived from analysis of cemeteries related to medieval leprosaria. ${ }^{18}$ The validity of leprosy diagnosis has, however, been questioned because in the Middle Ages, many rashes, including psoriasis and even syphilis, were confused with and assumed to be leprosy. ${ }^{1}$ Closure by Pope Clement in 1490 and 1505 of 10000 leprosaria with perhaps 100 individuals per institution ${ }^{19}$ suggests the presence of a million afflicted individuals. Those numbers are too great for leprosy (leprosy was just not that common), but certainly compatible with psoriasis, ${ }^{16}$ as $10 \%$ of individuals with psoriasis have psoriatic arthritis, a form of spondyloarthropathy. ${ }^{13}$ Prior studies on 500 year old cemeteries in Guam had diagnosed leprosy, whereas one of us (BMR) recognised that spondyloarthropathy was actually the disease present. ${ }^{20}$ The current study confirms the osseous changes of leprosy and spondyloarthropathy, identifies sources of confusion in their differential diagnosis, and identifies findings that distinguish between them.

Assessment of the origins of disease requires its recognition in the skeletal record. This study provides evidential guidelines for recognition of neuropathic disease, and for distinguishing among these diseases and between these and non-neuropathic disorders with superficially similar pedal manifestations.

\section{Clincial implications}

The failure of alignment of fracture components in leprosy matches that of neurosyphilis. Perhaps this is the result of prominent loss of position sense in those groups, uncommon in diabetes, in our experience. Spondyloarthropathy and leprosy had contrasting tuft whittling and resorption patterns, suggesting more concentric bone atrophy in spondyloarthropathy and less distal segment (perhaps on the basis of fragmentation) in leprosy and scleroderma. This contrasts with diaphyseal whittling (and its penultimate, the pencil in cup deformity), which was much more common in leprosy and spondyloarthropathy. The whittling in spondyloarthropathy was associated with retention of bone density, while that of leprosy was associated with osteopenia, further distinguishing these disorders.

Curiously, periosteal reaction was minimal, except in diabetes and spondyloarthropathy, with rare occurrence in leprosy. Periosteal reaction in leprosy, diabetes, and alcoholism was clearly related to adjacent soft tissue infection/ulcer, while that in spondyloarthropathy was apparently inherent to the disease. Further study is required to assess whether periosteal reaction is a direct effect of the enthseial component of the disease or a reaction to associated soft tissue events.

Increased frequency of any pedal fracture in diabetes and leprosy contrasts with the frequency of tuft divots in the two groups, but correlates if only aligned fractures are considered, suggesting a primary role of trauma. Curiously, the dramatic sensory changes of leprosy were associated with less injury than found in diabetes. This contrasts with stress fractures, divots, and flattening in alcoholism, suggesting a different operating mechanism. Clearly, the category "neuropathic arthropathy" does not define a single mechanism. Understanding of this complex disorder will require further careful characterisation of all aspects according to identified disease association. Electrophysiological and vascular studies will be of future interest, as well as expanding the scleroderma study sample.

\section{ACKNOWLEDGEMENTS}

Appreciation is expressed for facilitation of collection access by D Hunt and L Jellema, the staff of Southwoods X-ray, Youngstown, OH, USA for radiological assistance, and Y Masharawi for manuscript review.

\section{Authors' affiliations}

B M Rothschild, Arthritis Center of Northeast Ohio, Youngstown, $\mathrm{OH}$ 44512, USA; Professor of Medicine, Northeastern Ohio Universities College of Medicine, Rootstown, OH 44527, USA; Research Associate, Carnegie Museum of Natural History, Pittsburgh, PA 15213, USA; Research Associate, University of Kansas Museum of Natural History, Lawrence, KS 66045, USA 
S Behnam, Department of Internal Medicine, Humility of Mary Health System, Youngstown, OH 44501, USA; Department of Geriatric Medicine, John A Burns School of Medicine, University of Hawaii, Honolulu, HI 96817, USA

\section{REFERENCES}

1 Rothschild BM, Rothschild C. Postcranial skeletal manifestations of leprosy: Analysis findings in the pre- and post-modern treatment eras. J Clin Rheumatol $2001 ; 7: 228-37$.

2 Faget GH, Mayoral A. Bone changes in leprosy: A clinical and roentgenologic study of 505 cases. Radiology 1944:42:1-13.

3 Bruckner FE, Howell A. Neuropathic joints. Semin Arthritis Rheum 1972;2:47-69.

4 Sinha S, Munichoodappa CS, Kozak GP. Neuro-arthropathy (Charcot joints) in diabetes mellitus. Medicine 1972;51:191-210.

5 Resnick D. Diagnosis of bone and joint disorders. Philadelphia, Pennsylvania: Saunders, 2002.

6 Allman RM, Brower AC, Kotyarov EB. Neuropathic bone and joint disease. Radiol Clin Am 1988;26:1373-81

7 Clouse ME, Gramm HF, Legg M, Flood T. Diabetic osteoarthropathy. Am J Roent 1974;121:22-34.

8 Holt PJ. Rheumatological manifestations of diabetes mellitus. Clin Rheumatic Dis 1981;7:723-46.
9 Azerad E, Lubetzki J, Stuhl L, Slotine M. Les osteopathies du diabète sucré. L'ouest Medical 1964;17:529-63.

10 La Montagna G, Baruffo A, Tirri R, Buono G, Valentini G. Foot involvement in systemic sclerosis: A longitudinal study of 100 patients. Semin Arthritis Rheum 2002;31:248-55.

11 Scutellari PN, Orzincolo C, Lombardo F. La radiologia del piede nell alcolismo cronico. La Radiologia Medicva 1988;76:552-8.

12 Mensforth RP, Latimer BM. Hamann-Todd Collection aging studies: Osteoporosis fracture-syndrome. Am J Phys Anthropol 1989:80:461-79.

13 Koopman WJ. Arthritis and allied conditions, 13th ed. Baltimore: Williams \& Wilkins, 1997.

14 Faget GH, Mayoral A. Bone changes in leprosy: A clinical and roentgenologic study of 505 cases. Radiology 1944;42:1-13.

15 Feldman RA. Sturdivant M. Leprosy in Louisiana, 1855-1970. Am J Epidemiol 1975;102:303-10

16 Humes HD. Kelley's textbook of internal medicine, 4th ed. Philadelphia: Lippincott Williams \& Wilkins, 2000.

17 Anjum SN, Faisal M, Butt MS. Avascular necrosis with complete resorption of the proximal humerus following undisplaced three-part fracture. Orthopedics 2002;25:1288-9.

18 Moller-Christensen V. Bone changes in leprosy. Berlin, Germany: Munksgaard, 1961.

19 Holcomb RC. Christopher Columbus and the American origin of syphilis. US Nav Med Bull 1934:401-10.

20 Rothschild BM, Heathcote GM. Characterization of the skeletal manifestations of the treponemal disease Yaws as a population phenomenon. Clin Infect Dis 1993;17:198-203. 